\title{
Application of Resonant Nuclear Reactions for Studying the Diffusion of Nitrogen and Silicon in Ti-Modified Stainless Steel
}

\author{
J. Arunkumar, C. David, K. G. M. Nair, B. K. Panigrahi, and C. S. Sundar \\ Materials Science Group, Indira Gandhi Centre for Atomic Research, Kalpakkam 603 102, India \\ Correspondence should be addressed to K. G. M. Nair, kgmn@igcar.gov.in
}

Received 1 April 2011; Revised 13 June 2011; Accepted 17 June 2011

Academic Editor: Adam Georg Balogh

Copyright () 2012 J. Arunkumar et al. This is an open access article distributed under the Creative Commons Attribution License, which permits unrestricted use, distribution, and reproduction in any medium, provided the original work is properly cited.

\begin{abstract}
Resonant nuclear reaction analysis can be used for the study of diffusion behaviour of minor alloying elements in reactor structural materials. In the present paper, $\left.{ }^{15} \mathrm{~N}(\mathrm{p}, \alpha \gamma)\right)^{12} \mathrm{C}$ and ${ }^{30} \mathrm{Si}(\mathrm{p}, \gamma){ }^{31} \mathrm{P}$ reactions have been used to profile the ion-implanted ${ }^{15} \mathrm{~N}$ and ${ }^{30} \mathrm{Si}$ in D9 alloy (titanium-modified austenitic stainless steel). The diffusion coefficients at various temperatures have been estimated from the broadening of the implantation profiles during thermal annealing, and the activation energies are deduced.
\end{abstract}

\section{Introduction}

The structural materials like fuel clad and wrapper in sodium-cooled fast reactors are exposed to a hostile environment of intense fast neutron bombardment at elevated temperatures. One of the main problems which result on account of the radiation damage is the dimensional changes brought about by void swelling, leading to a decreased residence time of the fuel assemblies in the reactor core and lowering of fuel burnup. Therefore, resistance to void swelling is a major consideration in the choice of materials for the core components.

Improvement in the resistance to irradiation-induced void swelling can be achieved by the introduction of efficient traps for vacancies and helium such as dislocations and precipitate-matrix interfaces, by adjusting alloying elements and through thermomechanical treatments [1, 2]. The titanium-modified steel exhibits improved swelling resistance under breeder reactor conditions and, consequently, has become a prime candidate for structural applications [3]. The role of fast diffusing alloying elements, namely, $\mathrm{Ti}$, $\mathrm{Si}$, and $\mathrm{P}$ in suppressing void nucleation is known [4]. The fast diffusing species increases the effective vacancy diffusion coefficient, and the consequent reduction in the void nucleation rates plays a crucial role in imparting significant void swelling resistance to the alloy. In order to model such effects, knowledge of the diffusion behavior of constituent species is essential due to their considerable redistribution during irradiation. Therefore, thermal diffusion behavior of solutes like silicon and nitrogen in titanium-modified steels has been studied here.

Though some amount of studies on the effect of minor alloying elements on the self-diffusion of the constituent elements have been carried out [5], reports on the diffusion behavior of silicon in SS 316 are sparse, and to the best of our knowledge, there is hardly any literature describing the diffusion behavior of silicon in titanium-modified steels.

Also, studies concerning iron-based alloys and their variants with interstitial solute additions $(\mathrm{C}, \mathrm{N})$ continue to attract attention due to the rich technological interest in improving radiation resistance, mechanical and tribological properties. In nitriding processes involving ion implantation, an improvement in mechanical property is achieved due to the increased quantity of interstitial nitrogen and their interaction with crystal defects. There also exists an alternative conjecture that the trapping of vacancies with interstitial impurity atoms enhances the probability of recombination, hence aiding in reduction of void swelling. Thus, practical applications have necessitated a full understanding of the underlying physical processes involving interstitial solutes, 
namely, the phase formation, diffusion, trapping with vacancies, dislocations, and other second-phase particles during irradiation. This paper portrays the application of the resonance nuclear reaction analysis (RNRA) technique in understanding the phenomena related to defect-impurity interaction (vacancy-nitrogen complexes), solute and impurity diffusion ( $\mathrm{Si}$ and $\mathrm{N}$ thermal diffusion behaviour) in Timodified austenitic stainless steel.

\section{Experimental Details}

2.1. Sample Preparation and Ion Implantation. D9 is a titanium-modified austenitic stainless steel whose chemical composition is given in Table 1. The samples used for the experiments are spark cut from $20 \%$ cold-worked hexagonal wrappers. The samples were mechanically polished and subsequently subjected to solution annealing treatment which involves the heating of samples in vacuum at $1343 \mathrm{~K}$ for 30 minutes and subsequently at $1373 \mathrm{~K}$ for 5 minutes followed by furnace cooling. This solution annealing treatment ensures the samples to be free from the defect microstructure introduced during cold-work.

Solution-annealed D9 samples were implanted with $200 \mathrm{keV}^{30} \mathrm{Si}$ ions to a fluence of $3 \times 10^{16}$ atoms $\mathrm{cm}^{-2}$ using a $1.7 \mathrm{MV}$ tandetron accelerator at IGCAR, Kalpakkam. For nitrogen isotope implantation, solution-annealed D9 samples were implanted with $30 \mathrm{keV}^{15} \mathrm{~N}$ ions to a fluence of 5 $\times 10^{15}$ ions $\mathrm{cm}^{-2}$ using a low-energy ion implantation facility at GNS Science, New Zealand. Both silicon and nitrogen implantations were carried out at room temperature and at a vacuum level better than $\sim 1 \times 10^{-7}$ mbar.

2.2. Depth Profiling of Nitrogen and Silicon. The depth profiling of the implanted atoms has been carried out using narrow resonances of the nuclear reaction which are ideal for high depth resolution [6]. Depth profiling of ${ }^{15} \mathrm{~N}$ has been carried out using $429 \mathrm{keV}$ resonance of the ${ }^{15} \mathrm{~N}(\mathrm{p}, \alpha \gamma){ }^{12} \mathrm{C}$ reaction $\left(\Gamma \sim 120 \mathrm{eV}, E_{\gamma}=4.43 \mathrm{MeV}\right)$ and that of ${ }^{30} \mathrm{Si}$ using $620 \mathrm{keV}$ resonance $\left(\Gamma \sim 68 \mathrm{eV}, E_{\gamma}=7.9 \mathrm{MeV}\right)$ of the ${ }^{30} \mathrm{Si}(\mathrm{p}, \gamma)^{31} \mathrm{P}$ nuclear reaction. The applicability of these reactions in obtaining quantitative high-resolution depth profiles of nitrogen and silicon in a material is well known [7, 8]. The profiling experiments involve increasing incident proton energies beyond the resonance energy in steps of $1 \mathrm{keV}$, and collecting the gamma rays using a $3^{\prime \prime} \times 3^{\prime \prime}$ $\mathrm{NaI}$ detector serves as the signal for depth profiling the implanted species. The gamma ray yield is proportional to the concentration of the implanted atoms at depths described by the incident energy. The relationship between the incident energy and the depth at which the reaction is taking place can be established by taking into account the energy loss of protons in the alloy. Since both reactions have a very narrow resonance width, the depth resolution for either reactions is estimated to be $\sim 3 \mathrm{~nm}$ at the surface. The concentration of $\mathrm{Si}$ and $\mathrm{N}$ at the peak of the implantation depth profiles is $\sim 5$ at $\%$ and $\sim 3$ at $\%$, respectively.

2.3. Diffusion of Nitrogen and Silicon. For nitrogen diffusion studies, the samples were isochronally annealed in vacuum
TABLe 1: D9 composition (in weight \%).

\begin{tabular}{lccc}
\hline Element & wt $\%$ & Element & wt\% \\
\hline $\mathrm{Cr}$ & $14.0 \pm 0.5$ & $\mathrm{Ni}$ & $15.0 \pm 0.5$ \\
$\mathrm{Mo}$ & $2.20 \pm 0.05$ & $\mathrm{Mn}$ & $1.90 \pm 0.05$ \\
$\mathrm{Si}$ & $0.75 \pm 0.05$ & $\mathrm{Ti}$ & $0.25 \pm 0.005$ \\
$\mathrm{C}$ & $0.037 \pm 0.005$ & $\mathrm{~V}$ & $0.05 \pm 0.003$ \\
$\mathrm{Co}$ & $0.020 \pm 0.005$ & $\mathrm{Cu}$ & $<0.05$ \\
$\mathrm{Al}$ & $<0.05$ & $\mathrm{~S}$ & $<0.005$ \\
$\mathrm{P}$ & $<0.014$ & $\mathrm{Nb}$ & $<0.016$ \\
$\mathrm{Ta}$ & $<0.02$ & $\mathrm{~N}$ & $<0.005$ \\
$\mathrm{As}$ & $<0.034$ & $\mathrm{~B}$ & $10-20 \mathrm{ppm}$ \\
$\mathrm{Fe}$ & Balance & & \\
\hline
\end{tabular}

$\left(\sim 1 \times 10^{-6}\right.$ mbar $)$ from the ambient to $973 \mathrm{~K}$ in steps of $50 \mathrm{~K}$ for a period of $30 \mathrm{~min}$. At the end of each annealing step, the samples were quenched using a jet of cooled helium gas. Similarly for silicon diffusion studies, the samples were vacuum annealed up to $873 \mathrm{~K}$ in steps of $50 \mathrm{~K}$ isochronally (30 min). However, for obtaining diffusion profiles at temperatures greater than $873 \mathrm{~K}$, separate sets of samples were implanted under similar irradiation condition and annealed in a tubular furnace under vacuum $\left(\sim 1 \times 10^{-6} \mathrm{mbar}\right)$. These identical samples have been annealed from $873 \mathrm{~K}$ to $1073 \mathrm{~K}$ in steps of $50 \mathrm{~K}$ at different annealing time in order to obtain a measurable broadening of the depth profiles.

\section{Results and Discussion}

The experimental depth profile of ${ }^{15} \mathrm{~N}$ in D9 steel obtained by RNRA is shown in Figure 1(a). The depth profile exhibits an asymmetric Gaussian profile near the surface, and the experimental data has been fitted into two Gaussians with a variance of 0.95 . SRIM simulation [9] of $30 \mathrm{keV}$ nitrogen ions incident on steel shows that the peak damage and the projected range are located around $20 \mathrm{~nm}$ and $40 \mathrm{~nm}$, respectively (Figure $1(\mathrm{~b})$ ). The peak position of the fitted Gaussians coincides with the peak damage region and the projected range of implantation, defined by the SRIM simulation. It is observed that a part of implanted nitrogen atoms is located around the peak damage region in addition to being present at the predicted range of implantation. The redistribution occurs in order to relieve the stress caused by the $\mathrm{N}^{+}$implantation possibly forming vacancy-nitrogen complexes. In order to explore this possibility, the depth profile of implantation-induced vacancy defects has been probed using positron annihilation spectroscopy. From the changes observed in the defect-sensitive S-parameter, the evidence for the formation of vacancy-nitrogen complexes in the peak damage region was revealed [10].

The as-implanted sample was subjected to isochronal annealing in steps of $50 \mathrm{~K}$, and it was found that there was no significant alteration of the nitrogen concentration profile up to $823 \mathrm{~K}$ as compared to the as implanted profile. However, beyond this temperature, the profile broadens and extends into the depth of the sample, while the nitrogen concentration remains almost constant near the surface 


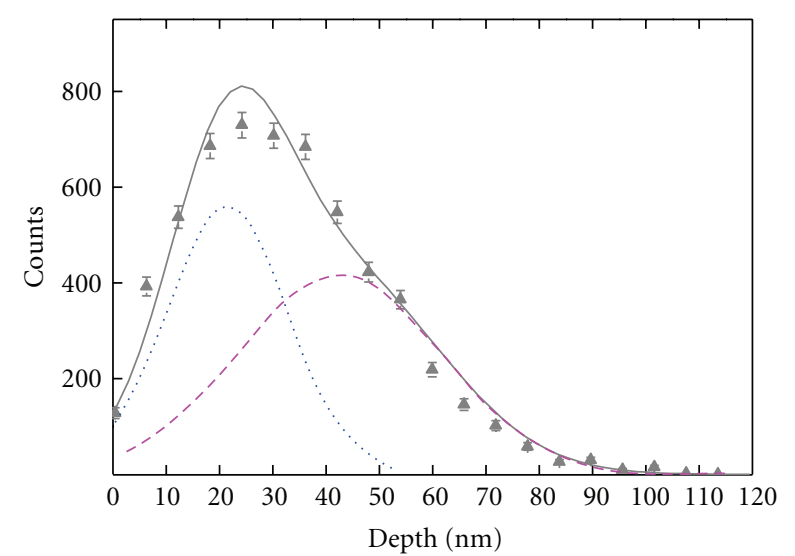

(a) Experimental

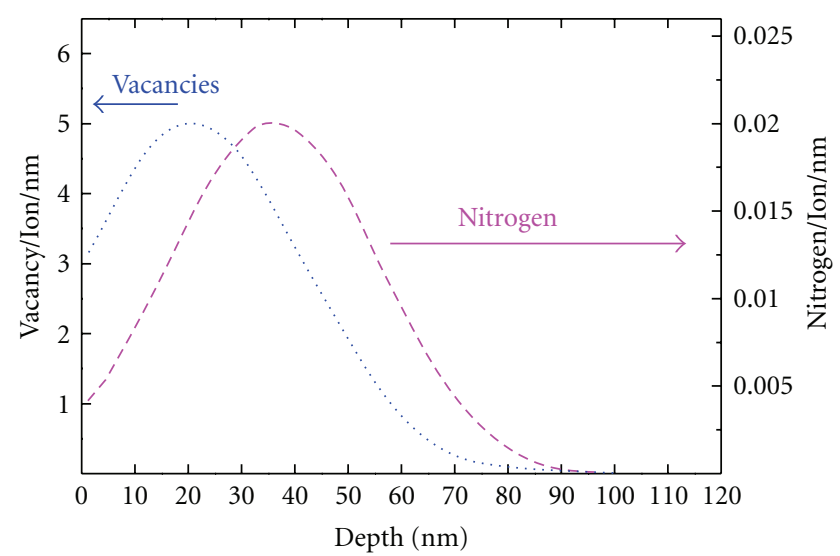

(b) SRIM calculated

Figure 1: (a) Experimental depth profile of ${ }^{15} \mathrm{~N}$ implanted in steel to a fluence of $5 \times 10^{15} \mathrm{~N} / \mathrm{cm}^{2}$ obtained using RNRA. The experimental data points (closed triangle) are fitted into two Gaussians whose peaks are centered at $\sim 20 \mathrm{~nm}$ (dotted line) and $42 \mathrm{~nm}$ (dashed line). (b) SRIM simulation of $30 \mathrm{keV}$ nitrogen in steel depicting the implanted ion and vacancy profiles.

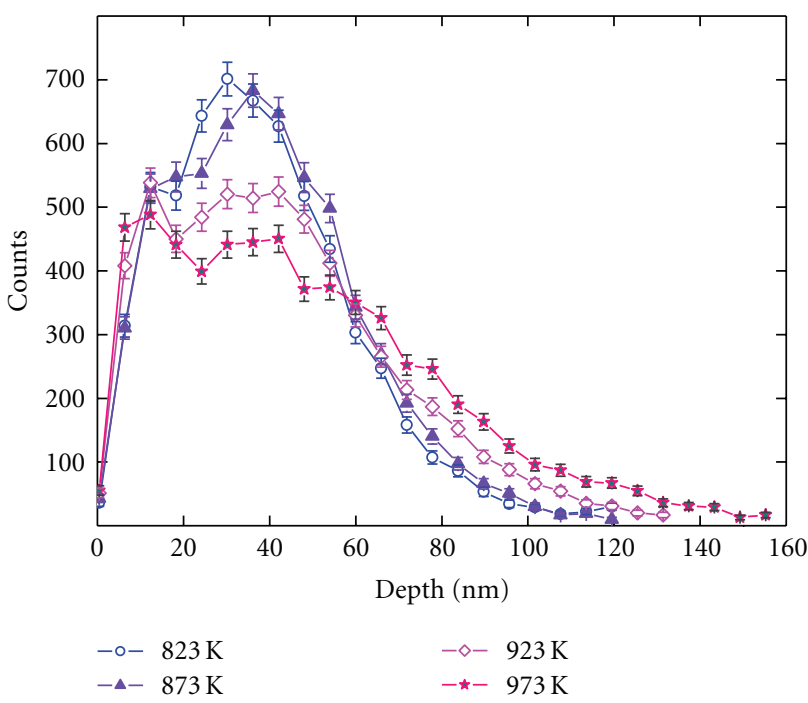

Figure 2: Depth profile of implanted nitrogen after annealing the same sample at $823 \mathrm{~K}, 873 \mathrm{~K}, 923 \mathrm{~K}$, and $973 \mathrm{~K}$ for 30 min duration.
(Figure 2). The profile broadening of the as-implanted sample (Gaussian distribution) can be used to deduce the diffusion coefficient $D$ by knowing the width of the implantation profile. In the present case, as the implantation profile is asymmetric and close to the surface, the implanted nitrogen was assumed as a thin source which diffuses into the bulk during annealing. Therefore, the following expression for the diffusion from an infinitely thin source into a semiinfinite medium is used $[11,12]$. The concentration $C$ at the depth $x$ after annealing the sample for time $t$ is

$$
C=A \exp \left(\frac{-x^{2}}{4 D t}\right),
$$

where $D$ is the diffusion coefficient. The plot of $\ln C$ versus $x^{2}$ gives the nitrogen penetration profiles in steel (Figure 3 ). The diffusion coefficient can be calculated from the slope of the penetration profiles [12]

$$
D=\left(\frac{p-p_{0}}{4 p p_{0} t}\right),
$$

where $p_{0}$ and $p$ are the slopes of penetration profiles before and after annealing at a temperature $T$. The major uncertainty in the calculation of diffusion coefficients arises from obtaining straight line fits to the penetration profiles, and it is estimated to be $\sim 5 \%$. Table 2 gives the diffusion coefficients of nitrogen in D9 at various temperatures. From the Arrhenius plot of $\ln D$ versus $(k T)^{-1}$, the effective activation energy $\left(E_{a}\right)$ for nitrogen diffusion in steel is estimated to be $0.9 \mathrm{eV}$ (Figure 4). This value is comparable to the activation energy derived in austenitic stainless steels involving low-energy ion implantation $(\sim 1 \mathrm{keV}): 0.8 \mathrm{eV}$ [13], $1 \mathrm{eV}$ [14] and plasma nitriding: $1.07 \mathrm{eV}$ [15]. Although nitrogen diffusion in these cases was obtained at elevated substrate temperatures under irradiation conditions, the activation energies were calculated from the penetration of nitrogen from the surface into the bulk of the sample which is similar to the method employed here. Comparing the activation energy obtained in the present studies with other postimplantation annealing studies in similar austenitic steel [16], it is found that the present value is much lower. On studying the annealing behavior of implanted nitrogen (40 keV) in austenitic stainless steel (SS316), Hirvonen and Anttila determined the activation energy to be $1.87 \mathrm{eV}$ [16]. In their study [16], nitrogen was implanted to a fluence of $7.5 \times 10^{16}$ ions $/ \mathrm{cm}^{2}$, where there could be trapping of nitrogen due to the possible formation of $\mathrm{V}-\mathrm{N}$ complexes in great extent, and also when nitrogen is in excess, precipitates can form hindering the movement of nitrogen. In the present case also, we inferred from the positron experiments that there is trapping of nitrogen at vacancies [10]. This could give rise to a decrease in the concentration of free nitrogen available for diffusion. We observe that there is no significant change in the near-surface concentration of nitrogen. This suggests that the $\mathrm{V}-\mathrm{N}$ complexes remain immobile and the observed diffusion is due to the free interstitial nitrogen. At higher annealing temperatures, the $\mathrm{V}-\mathrm{N}$ complexes might become mobile, or a breakup of the complexes is possible. 


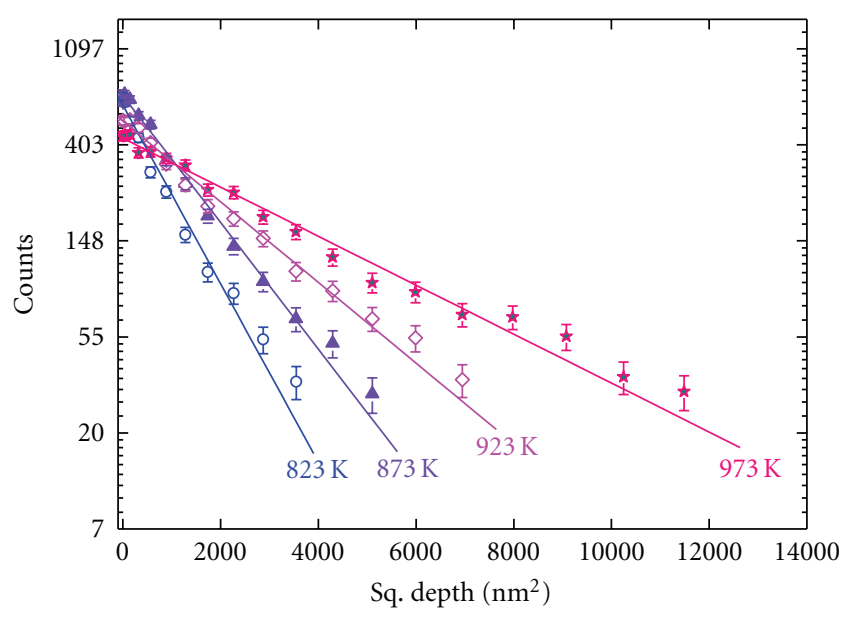

Figure 3: Penetration profiles ( $\ln C$ versus $x^{2}$ ) derived from depth profiles of nitrogen obtained after annealing at different temperatures in D9 steel.

TABle 2: Diffusion coefficients of $\mathrm{N}$ in D9.

\begin{tabular}{lcc}
\hline Temperature $(\mathrm{K})$ & Time $\left(10^{3} \mathrm{sec}\right)$ & Diffusion coefficient $\left(\mathrm{m}^{2} / \mathrm{sec}\right)$ \\
\hline 873 & 1.8 & $6.1 \times 10^{-16}$ \\
923 & 1.8 & $1.2 \times 10^{-15}$ \\
973 & 1.8 & $2.1 \times 10^{-15}$ \\
\hline
\end{tabular}

TABle 3: Diffusion coefficients of Si in D9.

\begin{tabular}{lcc}
\hline Temperature $(\mathrm{K})$ & Time $\left(10^{3} \mathrm{sec}\right)$ & Diffusion coefficient $D\left(\mathrm{~m}^{2} / \mathrm{sec}\right)$ \\
\hline 873 & 39.6 & $4.6 \times 10^{-20}$ \\
923 & 18 & $1.3 \times 10^{-19}$ \\
973 & 3.6 & $8.8 \times 10^{-19}$ \\
1023 & 3.6 & $2.6 \times 10^{-18}$ \\
1073 & 0.9 & $6.5 \times 10^{-18}$ \\
\hline
\end{tabular}

In fact, small changes in the near surface composition of nitrogen is observed as a function of annealing temperature, and a more detailed study of this might throw light on the evolution of the nitrogen trapped at vacancies.

Proceeding to the next study in ${ }^{30} \mathrm{Si}$-implanted D9 samples, the experimentally obtained depth distribution of the as-implanted silicon is illustrated in Figure 5, which is a Gaussian profile with centre and full width at halfmaximum (FWHM) as $120 \mathrm{~nm}$ and $95 \mathrm{~nm}$, respectively. The experimentally determined depth profile is in good agreement with the theoretical profile computed from SRIM program [9]. It should be noted here that there is no redistribution of implanted silicon quite contrary to the observation in nitrogen implantation. The absence of such a redistribution of the implanted silicon may be due to the presence of silicon in substitutional position of the host lattice. This implanted silicon distribution serves as the marker layer, and its broadening is used for following the diffusion behavior of silicon in D9 samples.

The silicon implanted sample was annealed in steps of $50 \mathrm{~K}$ in vacuum for a period of $30 \mathrm{~min}$ at each step followed by RNRA experiments after each annealing. It is found that

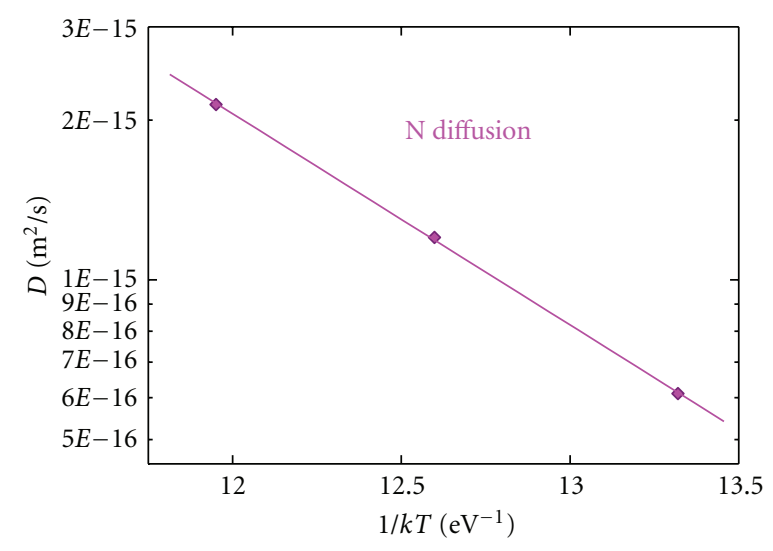

FIGURE 4: Arrhenius plot to estimate activation energy for nitrogen diffusion in D9 steel.

there is no significant change in the width of the implanted profile in the sample up to $873 \mathrm{~K}$ with the annealing time of half an hour. After prolonged annealing at $873 \mathrm{~K}$ for few hours followed by RNRA experiment at different increments of time, the implantation profile showed a discernible change after eleven hours (Figure 5). Further, four numbers of Siimplanted D9 samples were annealed independently at four different temperatures from $923 \mathrm{~K}$ to $1073 \mathrm{~K}$ in steps of $50 \mathrm{~K}$ for different durations. Figure 5 shows the diffusion profile of silicon in the temperature interval of $873 \mathrm{~K}$ to $1073 \mathrm{~K}$, and the annealing time for each temperature is indicated in the figure. At higher annealing temperatures beyond $973 \mathrm{~K}$, segregation of Si towards the surface is also observed. However, broadening of depth profiles in this temperature regime is quite evident. The method used for estimating $\mathrm{N}$ diffusion coefficients is employed for Si diffusion also. Figure 6 shows the penetration profiles of $\mathrm{Si}$ in D9 at various temperatures with the respective annealing time. The accuracy of the calculated $D$ values is limited by the linear fitting of the slopes (error less than $\sim 10 \%$ ). The diffusion coefficients at different annealing temperatures are tabulated in Table 3. From the Arrhenius plot of $\ln D$ versus the inverse of $k T$ (Figure 7), activation energy of $2.1 \mathrm{eV}$ is obtained for the silicon diffusion in D9 steel.

The activation energy for silicon diffusion in the present experiment may be compared to the self-diffusion energy of iron $(2.84 \mathrm{eV})$ in fcc-Fe [17], and it is also comparable with the diffusion of alloying elements like nickel $(2.72 \mathrm{eV})$, iron $(2.60 \mathrm{eV})$, and chromium $(2.51 \mathrm{eV})$ reported in austenitic stainless steel [5]. In addition, the activation energy deduced here for silicon diffusion is much greater than the experimentally determined effective vacancy migration energy $(1.13 \mathrm{eV})$ in solution-annealed D9 steel [18]. Hence, silicon diffusion in the solution annealed D9 steel is regarded to be a vacancy-assisted mechanism. The present value of activation energy for silicon diffusion is lower than a previously reported value of $2.43 \mathrm{eV}$ for silicon diffusion in fcc-Fe [17]. Addition of fast diffusing solutes can increase the vacancy migration and in turn the diffusion of solvent atoms. Evidences exist in the literature with respect to the increase 


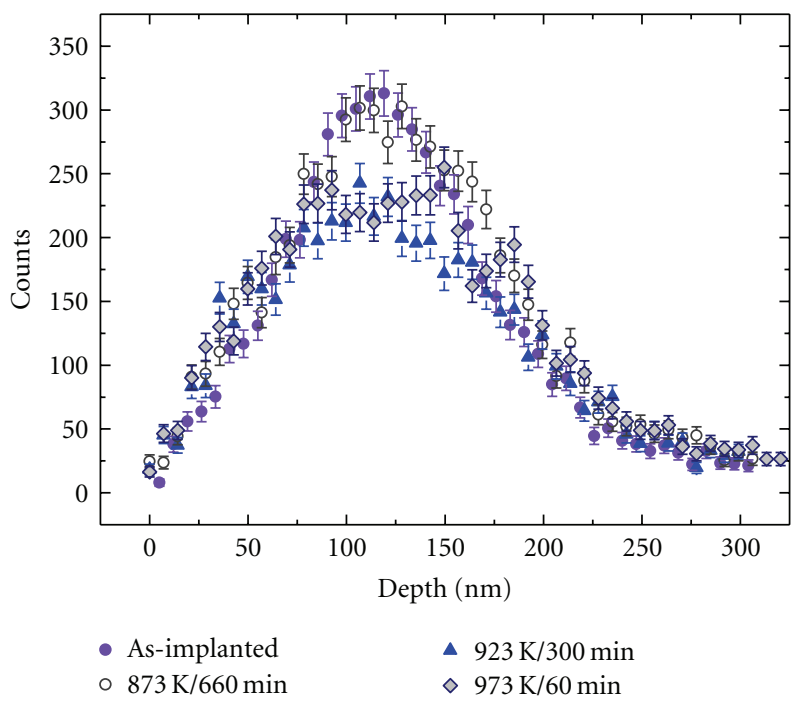

(a)

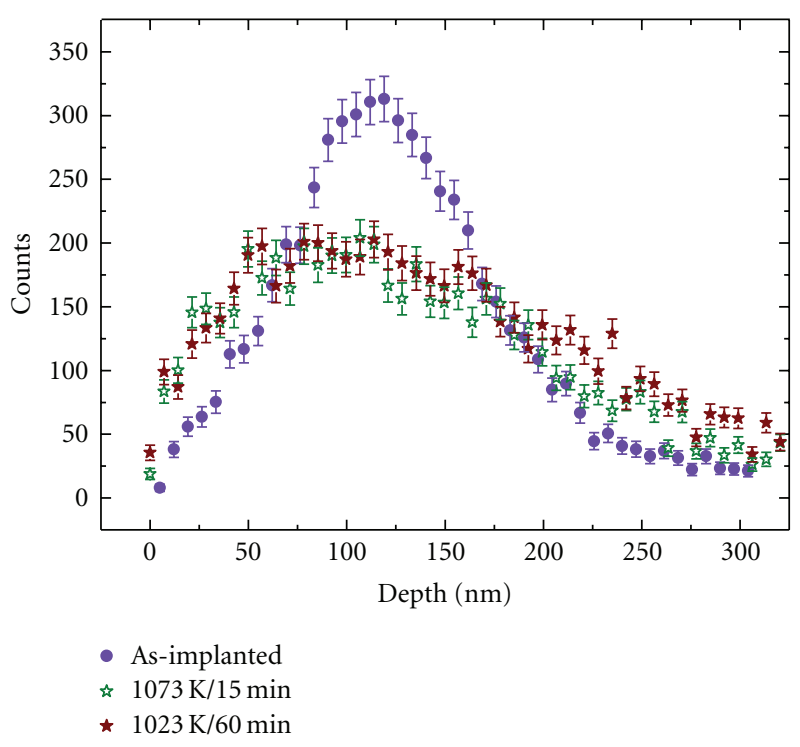

(b)

FIgURE 5: The broadening of the depth profile of implanted ${ }^{30} \mathrm{Si}$ determined by RNRA measurements at different annealing temperatures.

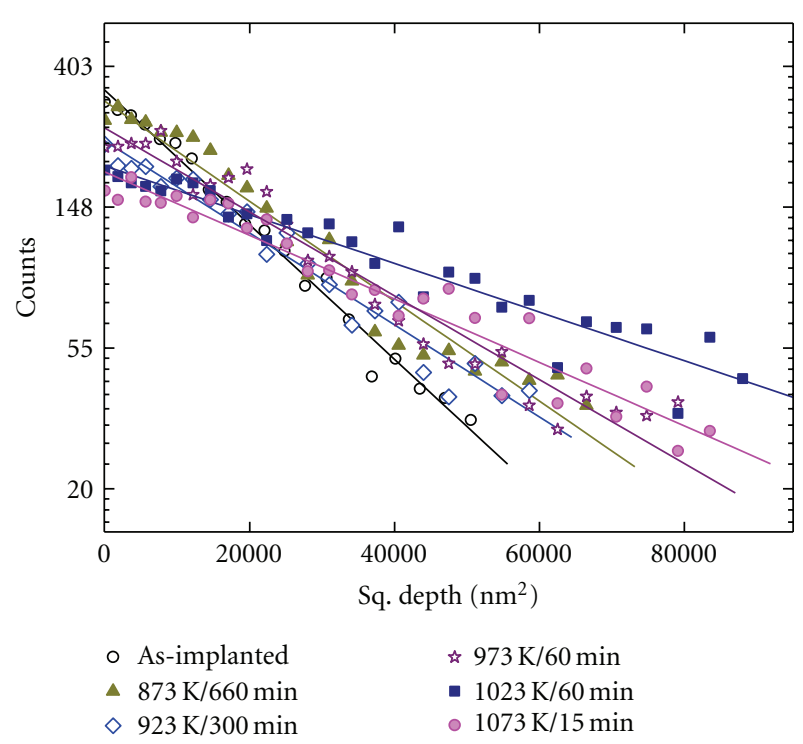

FIGURE 6: Penetration profiles of the silicon obtained after annealing the independently implanted samples at different temperatures in D9 steel.

in the diffusivity of major alloying elements like $\mathrm{Fe}, \mathrm{Cr}$, and $\mathrm{Ni}$ due to silicon additions $[5,19]$. It should be noted that another fast diffusing species, namely titanium is present in D9 steel. Titanium being an oversized element in the D9 alloy would diffuse via vacancy mechanism. In a work by Okita et al. [20] to understand the effect of titanium on void swelling, studies were carried out on solution-annealed austenitic Fe-15Cr-16Ni ternary alloys (similar wt\% of $\mathrm{Cr}$ and $\mathrm{Ni}$ in $\mathrm{D} 9$ steel) without titanium and with the addition of $0.25 \mathrm{wt} \%$ of $\mathrm{Ti}$ (similar wt\% of $\mathrm{Ti}$ in $\mathrm{D} 9$ steel). In that paper [20], reduction in void nucleation due to titanium

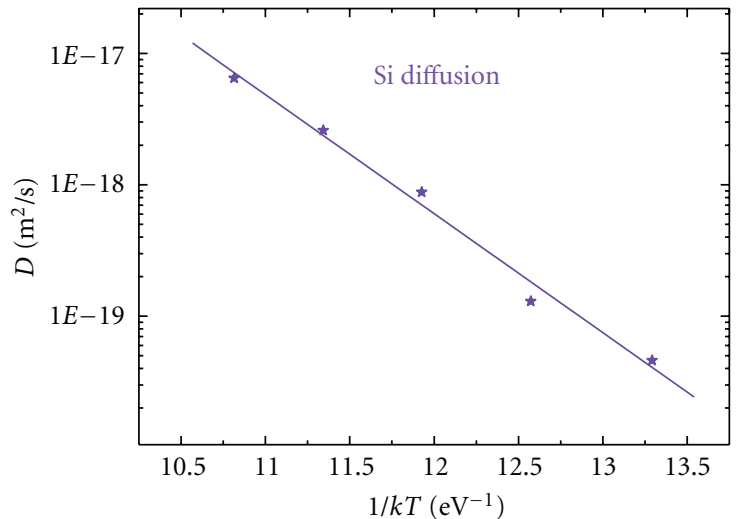

Figure 7: Arrhenius plot for the determination of activation energy for Si diffusion in D9 steel.

addition was attributed to the enhancement of the effective vacancy diffusion coefficient. Hence, the reason for the relatively lower activation energy obtained here for silicon diffusion in solution-annealed D9 steel is ascribed to the increased vacancy migration due to the presence of both silicon and titanium in D9 steels. Therefore, the present observation strongly suggests that the synergetic effects due to the presence of various fast diffusing solutes contribute to enhanced vacancy mobility and the consequent void swelling suppression.

\section{Conclusions}

Resonant nuclear reaction analysis has been utilized to obtain the diffusion profiles of nitrogen and silicon in Ti-modified stainless steel. Results show that in the temperature range of annealing, a fraction of nitrogen remains trapped near 
the surface possibly vacancy-nitrogen complexes, and the activation energy for diffusion of free nitrogen is obtained. The thermal diffusion behavior of silicon in titaniummodified steel is also determined. From the estimated activation energy, it can be concluded that in a thermal environment silicon diffuses by vacancy mechanism in steel.

\section{Acknowledgment}

The authors gratefully acknowledge Dr. John Kennedy, Senior Scientist, National Isotope Centre, GNS Science, New Zealand for nitrogen implantation.

\section{References}

[1] L. K. Mansur, E. H. Lee, P. J. Maziasz, and A. P. Rowcliffe, "Control of helium effects in irradiated materials based on theory and experiment," Journal of Nuclear Materials, vol. 141143, no. 2, pp. 633-646, 1986.

[2] W. Kesternich, "A possible solution of the problem of helium embrittlement," Journal of Nuclear Materials, vol. 127, no. 2-3, pp. 153-160, 1985.

[3] A. F. Rowcliffe and M. L. Grossbeck, "The response of austenitic steels to radiation damage," Journal of Nuclear Materials, vol. 122-123, no. 1-3, pp. 181-190, 1984.

[4] P. J. Maziasz, "Void swelling resistance of phosphorusmodified austenitic stainless steels during HFIR irradiation at $300-500^{\circ} \mathrm{C}$ to $57 \mathrm{dpa}$," Journal of Nuclear Materials, vol. 200, no. 1, pp. 90-107, 1993.

[5] W. Assassa and P. Guiraldenq, "Bulk and grain boundary diffusion of ${ }^{59} \mathrm{Fe},{ }^{51} \mathrm{Cr}$ and ${ }^{63} \mathrm{Ni}$ in austenitic stainless steel under the influence of silicon content," Metal Science, vol. 12, no. 3, pp. 123-128, 1978.

[6] B. Maurel, G. Amsel, and J. P. Nadai, "Depth profiling with narrow resonances of nuclear reactions: theory and experimental use," Nuclear Instruments and Methods In Physics Research, vol. 197, no. 1, pp. 1-13, 1982.

[7] S. Kumar, S. V. Kumar, G. L. N. Reddy, V. Kain, J. V. Ramana, and V. S. Raju, "Depth profiling of nitrogen using $429 \mathrm{keV}$ and $897 \mathrm{keV}$ resonances in the ${ }^{15} \mathrm{~N}(\mathrm{p}, \alpha \gamma){ }^{12} \mathrm{C}$ reaction," Nuclear Instruments and Methods in Physics Research, Section B, vol. 240, no. 3, pp. 704-710, 2005.

[8] D. J. Cherniak, "Silicon self-diffusion in single-crystal natural quartz and feldspar," Earth and Planetary Science Letters, vol. 214, no. 3-4, pp. 655-668, 2003.

[9] J. F. Ziegler, J. P. Biersack, and U. Littmark, The Stopping and Range of Ions in Solids, Pergamon, New York, NY, USA, 1985.

[10] J. Arunkumar, C. David, C. Varghese Anto et al., "A study on the redistribution of ion-implanted nitrogen in Ti-modified austenitic steel," Journal of Nuclear Materials, vol. 414, no. 3, pp. 382-385, 2011.

[11] J. Crank, Mathematics of Diffusion, Clarendon, Oxford, UK, 1975.

[12] F. L. Bregolin, M. Behar, and F. Dyment, "Diffusion study of nitrogen implanted into $\alpha$-Hf using the nuclear resonance technique," Applied Physics A, vol. 95, no. 2, pp. 501-505, 2009.

[13] D. L. Williamson, J. A. Davis, P. J. Wilbur, J. J. Vajo, R. Wei, and J. N. Matossian, "Relative roles of ion energy, ion flux, and sample temperature in low-energy nitrogen ion implantation of Fe-Cr-Ni stainless steel," Nuclear Instruments and Methods in Physics Research, Section B, vol. 127-128, pp. 930-934, 1997.
[14] N. Tsubouchi, Y. Mokuno, A. Chayahara, and Y. Horino, "Nitrogen diffusion in stainless steel during irradiation with mass-selected low-energy $\mathrm{N}^{+}$ion beams," Surface and Coatings Technology, vol. 196, no. 1-3, pp. 271-274, 2005.

[15] E. Menthe and K. T. Rie, "Further investigation of the structure and properties of austenitic stainless steel after plasma nitriding," Surface and Coatings Technology, vol. 116119, pp. 199-204, 1999.

[16] J. Hirvonen and A. Anttila, "Annealing behavior of implanted nitrogen in AISI 316 stainless steel," Applied Physics Letters, vol. 46, no. 9, pp. 835-836, 1985.

[17] D. Bergner, Y. Khaddour, and S. Lorx, "Diffusion of Si in bccand fcc-Fe," Defect and Diffusion Forum, vol. 66-69, pp. 14071412, 1990.

[18] J. Arunkumar, S. Abhaya, R. Rajaraman et al., "Defect recovery in proton irradiated Ti-modified stainless steel probed by positron annihilation," Journal of Nuclear Materials, vol. 384, no. 3, pp. 245-248, 2009.

[19] S. J. Rothman, L. J. Nowicki, and G. E. Murch, "Self-diffusion in austenitic Fe-Cr-Ni alloys," Journal of Physics F: Metal Physics, vol. 10, no. 3, article 009, pp. 383-398, 1980.

[20] T. Okita, W. G. Wolfer, F. A. Garner, and N. Sekimura, "Effects of titanium additions to austenitic ternary alloys on microstructural evolution and void swelling," Philosophical Magazine, vol. 85, no. 18, pp. 2033-2048, 2005. 

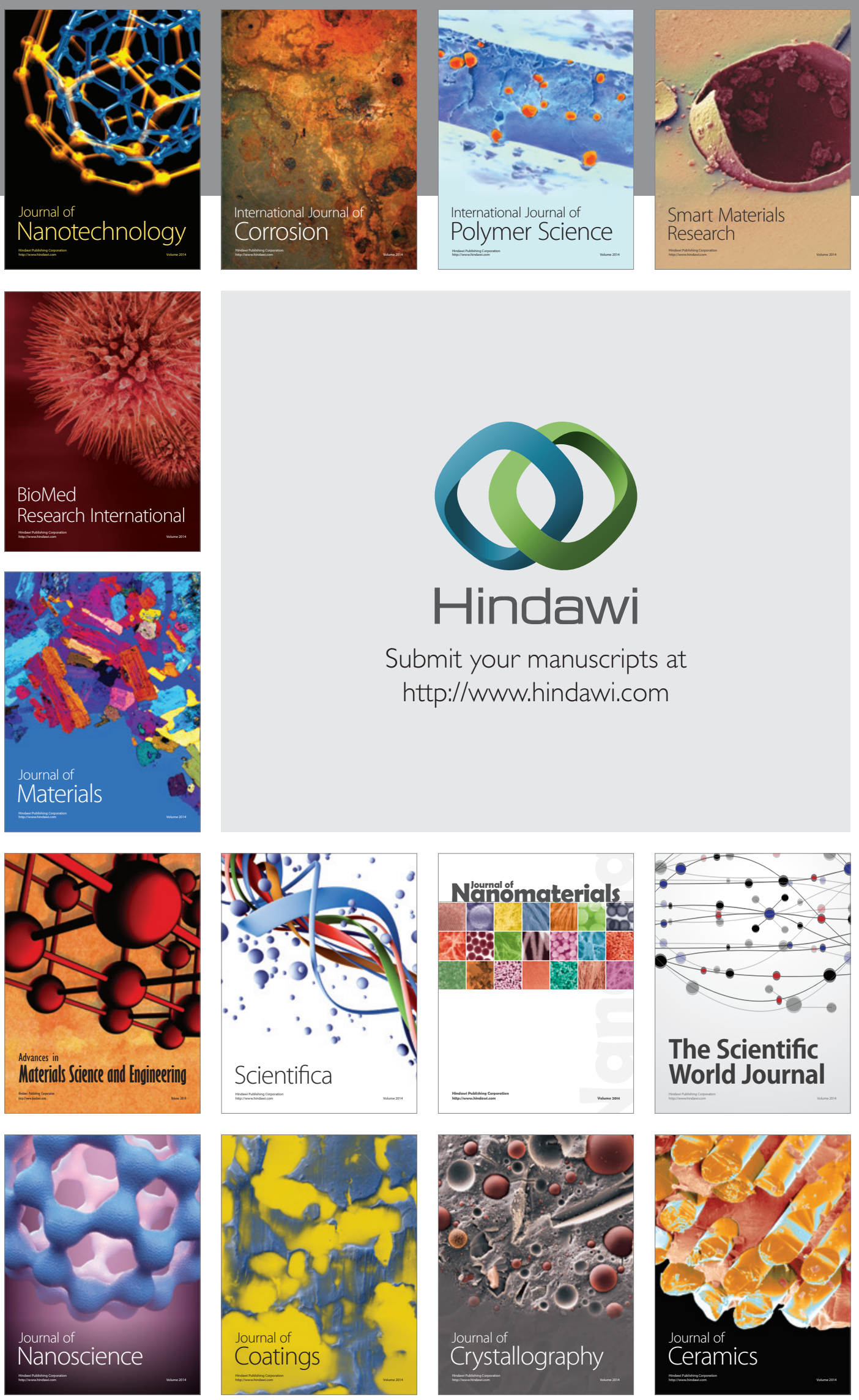

The Scientific World Journal

Submit your manuscripts at

http://www.hindawi.com

\section{World Journal}

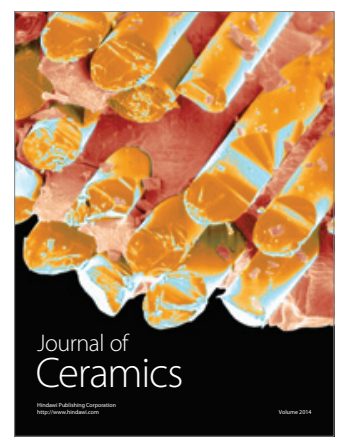

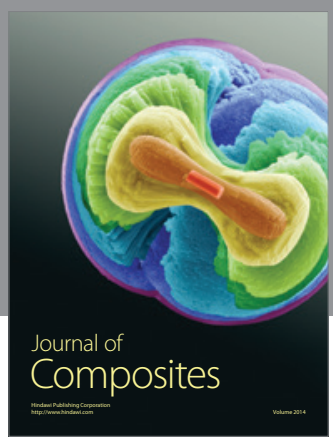
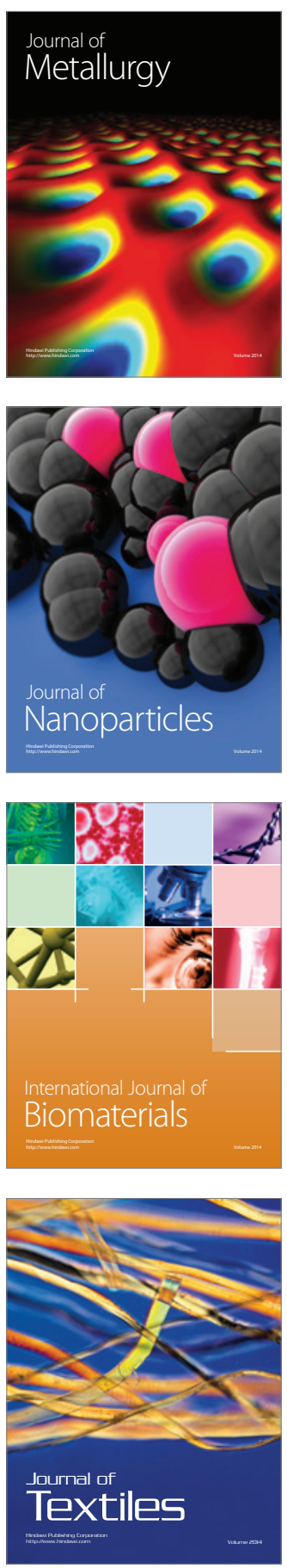